\title{
Papers
}

\section{Medically unexplained symptoms in frequent attenders of secondary health care: retrospective cohort study}

Steven Reid, Simon Wessely, Tim Crayford, Matthew Hotopf

\begin{abstract}
Objective To estimate the prevalence of medically unexplained symptoms in patients who most frequently attend outpatient services.

Design Retrospective cohort study over three years with review of case notes.

Setting Secondary care services in the South Thames (West) NHS region.

Participants Outpatient attenders with new appointments in 1993.

Main outcome measures Number of outpatient appointments, and number of consultation episodes for medically unexplained conditions.

Results Medical records of 361 of 400 sampled

frequent attenders were examined, and 971

consultation episodes were recorded. Ninety seven $(27 \%)$ had one or more consultation episodes in which the condition was medically unexplained; 208 (21\%) of the 971 consultation episodes were medically unexplained. Abdominal pain, chest pain, headache, and back pain were commonly found to be medically unexplained.

Conclusions Medically unexplained symptoms present in most hospital specialties and account for a considerable proportion of consultations by frequent attenders in secondary care.
\end{abstract}

\section{Introduction}

A small proportion of patients attending outpatient clinics in secondary care attend frequently and are responsible for a high proportion of healthcare costs. ${ }^{12}$ Early studies showed that many such patients consult for physical symptoms which, after extensive investigation, remain medically unexplained. ${ }^{3}$ These symptoms occur commonly in all medical settings, yet they remain poorly understood and are often persistent and disabling. ${ }^{4}$ There have been few studies of frequent attenders in secondary care. Previous work has been limited to single specialties and teaching hospitals ${ }^{5}$ or has focused on inpatient admissions. ${ }^{6}$

We examined the outpatient consultations of frequent attenders in all the general hospitals across one regional health authority and included both medical and surgical specialties. We estimated the prevalence of medically unexplained symptoms in those patients who most frequently attend outpatient services.

\begin{abstract}
Methods
South Thames (West) NHS region has recorded outpatient hospital activity in computerised form since 1991 and has a complete dataset for each acute sector provider since 1992. The system gives patients a unique identifier and records details of sex, age, and each outpatient referral (including the specialty and dates of subsequent appointments). To identify frequent attenders we defined a population in which potential subjects were all patients in the region aged 18-65 years who had a new appointment to secondary medical or surgical care in 1993 (index appointments). Index appointments were categorised according to specialty. We excluded specialties for specific conditions, such as obstetrics (but not gynaecology) and oncology, from the sample because referred patients were unlikely to be presenting with medically unexplained symptoms. Psychiatry was also excluded as in this case medically unexplained symptoms would be the reason for referral.

We followed patients with index appointments over

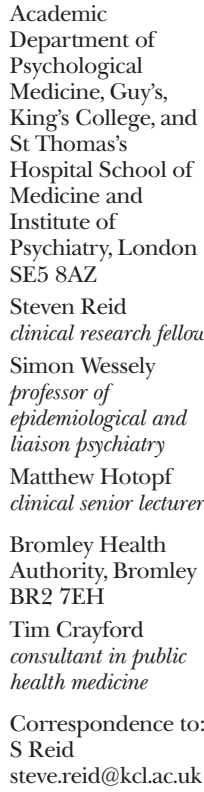
a three year period to assess their overall service use within the region by counting all outpatient appointments. The population was stratified by two age groups (18-45 years and 46-65 years) to account for the expected increased rates of consultation in the older age group. Frequent attenders were then defined as the top $5 \%$ of outpatient users in each age group.

We contacted all NHS trusts in the region and requested permission to examine the case notes of the identified frequent attenders. From the patients of those trusts that agreed to participate, we used a computer program to select randomly 200 from the total in each age group (24 489 aged 18-45 years; 36743 aged 46-65 years) for inclusion in the study. The study was approved by the local research ethics committee.

A consultation episode was defined as all appointments after referral and was completed after discharge, death, or referral elsewhere. The case notes were examined by a medically qualified investigator (SR) and information was obtained on the number of referrals for each patient and subsequent appointments. We recorded details of the reason(s) for referral and identified investigations and treatment received at each appointment. Finally, for each consultation episode the diagnosis was noted (if given) and it was determined whether the episode was medically unexplained, mixed (evidence of both physical and psychological disorder),
BMJ 2001;322:1-4 
Table 1 Characteristics of 361 frequent attenders by age group. Figures are number (percentage) of patients

\begin{tabular}{lcc} 
& $\begin{array}{c}\mathbf{1 8 - 4 5} \text { years } \\
(\mathbf{n = 1 8 9 )}\end{array}$ & $\begin{array}{c}\mathbf{4 6 - 6 5} \text { years } \\
\mathbf{( n = 1 7 2 )}\end{array}$ \\
\hline Sex: & $52(28)$ & $77(45)$ \\
\hline Men & $137(73)$ & $95(55)$ \\
\hline Women & & \\
\hline Employment: & $30(16)$ & $39(23)$ \\
\hline Manual & $81(43)$ & $37(22)$ \\
\hline Non-manual & $50(27)$ & $31(18)$ \\
\hline Housewife & $28(15)$ & $65(38)$ \\
\hline Retired/unemployed & & \\
\hline Marital status: & $59(31)$ & $122(13)$ \\
\hline Single & $115(61)$ & $11(6)$ \\
\hline Married/cohabiting & $12(6)$ & $17(10)$ \\
\hline Separated/divorced & $3(2)$ & $143(83)$ \\
\hline Widowed & & $29(17)$ \\
\hline Ethnic group: & $154(82)$ & \\
\hline White & $35(19)$ & \\
\hline Non-white & & \\
\hline
\end{tabular}

or factitious. Criteria for a medically unexplained episode were that the patient presented with physical symptoms, the patient received investigations for these symptoms, and the investigations and clinical examination revealed no abnormality or only abnormalities that were thought to be trivial or incidental.

A symptom was designated as definitely medically unexplained if there was evidence of a thorough investigation of the symptoms, with negative results, and either psychosocial reasons were suggested for the presentation or a diagnosis was made that implied a medically unexplained syndrome (for example, fibromyalgia, irritable bowel syndrome, etc). We used an intermediate category, probably medically unexplained, when there was an absence of evidence that a defined organic disease caused the symptom but uncertainty was expressed about the diagnosis or investigations were inconclusive. We evaluated this method in a pilot study involving both liaison psychiatrists and physicians and found it to have good interrater reliability ( $\kappa$ 0.76-0.88). ${ }^{7}$ It has also been used with similar reliability in a study of hospital admissions. ${ }^{8}$ For the purposes of analysis we regarded those episodes categorised as definitely or probably unexplained as medically unexplained. The prevalence of medically unexplained consultation episodes was calculated according to referral complaint and specialty.

\section{Results}

Of the 12 NHS trusts we contacted in the region, only one refused examination of its medical records. A total of $361(90 \%)$ sets of case notes were traced and obtained for examination: 189 (95\%) for patients aged 18-45 years and $172(86 \%)$ for patients aged 46-65. Of the remaining 39 sets, six were unavailable because of ongoing litigation or complaint, nine of the patients were dead, and 24 were recorded as missing. In total 971 consultation episodes were recorded. The median number of referrals (consultation episodes) over the three year period was 2 (range 1-8) and the overall median number of appointments was 18 (range 13-45).

Table 1 shows the demographic characteristics of the frequent attenders. Of the 361 patients, 97 (27\%) had one or more medically unexplained episodes. Of the 971 consultation episodes, 164 (17\%) were "definitely" medically unexplained, $44(5 \%)$ were "probably" medically unexplained, 30 (3\%) were mixed episodes, and $1(0.1 \%)$ was recorded as a factitious disorder.

Table 2 shows the referral complaints divided into 30 categories and the number of consultation episodes stratified by age and the percentage that were medically unexplained. For those frequent attenders with gastrointestinal complaints, patients in 73\% of the consultation episodes for abdominal pain or a change in bowel habit had medically unexplained symptoms. For over a quarter of the consultation episodes for pelvic pain there was no medical explanation, and when patients aged over 45 were excluded this figure rose to $35 \%$. Medically unexplained symptoms were common among all of the neurological complaints, accounting for $63 \%$ of headache referrals and $27 \%$ of referrals for seizures. This was also the case for musculoskeletal problems and in particular back pain, with $69 \%$ of referrals remaining unexplained.

Table 2 Prevalence of medically unexplained episodes in frequent attenders categorised by referral complaint (stratified by age). Figures are number of medically unexplained symptoms/number of referrals

\begin{tabular}{|c|c|c|}
\hline Referral complaint & $18-45$ years & $46-65$ years \\
\hline \multicolumn{3}{|l|}{ Gastrointestinal complaints: } \\
\hline Abdominal pain/change in bowel habit & $25 / 30$ & $14 / 23$ \\
\hline Others & $1 / 21$ & $0 / 26$ \\
\hline \multicolumn{3}{|l|}{ Gynaecological complaints: } \\
\hline Pelvic pain & $7 / 20$ & $0 / 6$ \\
\hline Others & $3 / 50$ & $1 / 12$ \\
\hline \multicolumn{3}{|l|}{ Neurological complaints: } \\
\hline Seizures & $2 / 7$ & $1 / 4$ \\
\hline Headache & $13 / 18$ & $4 / 9$ \\
\hline Others & $2 / 4$ & $1 / 10$ \\
\hline \multicolumn{3}{|l|}{ Musculoskeletal complaints: } \\
\hline Back pain & $14 / 19$ & $15 / 23$ \\
\hline Joint pain & $4 / 21$ & $6 / 39$ \\
\hline Fatigue & $6 / 11$ & $2 / 8$ \\
\hline Others & $4 / 23$ & $6 / 29$ \\
\hline \multicolumn{3}{|l|}{ Breast complaints: } \\
\hline Breast lump & $0 / 10$ & $0 / 24$ \\
\hline Mastalgia & $4 / 4$ & $0 / 1$ \\
\hline \multicolumn{3}{|l|}{ Urinary complaints: } \\
\hline Incontinence & $2 / 5$ & $5 / 20$ \\
\hline Others & $0 / 5$ & $0 / 5$ \\
\hline \multicolumn{3}{|l|}{ Endocrine complaints: } \\
\hline Diabetes & $0 / 9$ & $0 / 28$ \\
\hline Others & $0 / 34$ & $0 / 27$ \\
\hline \multicolumn{3}{|l|}{ Respiratory complaints: } \\
\hline Shortness of breath & $1 / 8$ & $1 / 6$ \\
\hline Others & $1 / 11$ & $1 / 11$ \\
\hline \multicolumn{3}{|l|}{ Cardiovascular complaints: } \\
\hline Chest pain & $25 / 31$ & $15 / 52$ \\
\hline Others & $1 / 13$ & $0 / 18$ \\
\hline \multicolumn{3}{|l|}{ Ear/nose/throat complaints: } \\
\hline Rhinitis & $1 / 5$ & $0 / 2$ \\
\hline Sinusitis & $1 / 9$ & $0 / 1$ \\
\hline Others & $5 / 30$ & $6 / 26$ \\
\hline Dental complaints & $1 / 11$ & $0 / 3$ \\
\hline \multicolumn{3}{|l|}{ Skin complaints: } \\
\hline Eczema & $0 / 4$ & $0 / 4$ \\
\hline Psoriasis & $0 / 11$ & $0 / 2$ \\
\hline Others & $0 / 30$ & $0 / 23$ \\
\hline Blood disorders & $0 / 10$ & $0 / 9$ \\
\hline Eye complaints & $3 / 20$ & $4 / 36$ \\
\hline
\end{tabular}


Table 3 Prevalence of medically unexplained episodes in frequent attenders categorised by specialty. ${ }^{*}$ Figures are number of medically unexplained symptoms/number of referrals

\begin{tabular}{lc} 
Specialty & No \\
\hline General surgery & $19 / 115$ \\
\hline Gynaecology & $19 / 110$ \\
\hline Ear, nose, throat & $24 / 88$ \\
\hline Ophthalmology & $9 / 77$ \\
\hline General medicine & $8 / 76$ \\
\hline Rheumatology & $22 / 67$ \\
\hline Dermatology & $1 / 62$ \\
\hline Gastroenterology & $32 / 59$ \\
\hline Orthopaedics & $15 / 50$ \\
\hline Neurology & $20 / 40$ \\
\hline Chest medicine & $6 / 39$ \\
\hline Cardiology & $13 / 38$ \\
\hline
\end{tabular}

*Data shown for 12 specialties receiving most referrals.

Table 3 shows the prevalence of medically unexplained symptoms in frequent attenders among specialty outpatient clinics. Medically unexplained symptoms occurred commonly in all of the specialties shown with the exception of dermatology. Gastroenterology and neurology had a particularly high rate, with at least $50 \%$ of referrals remaining medically unexplained.

\section{Discussion}

In this study of medically unexplained symptoms we found that such symptoms are common in patients who frequently attend several secondary care specialties. Most previous studies on this issue have focused on primary care settings. By looking at secondary medical care, we have used a population that has been extensively investigated, thus affording a greater degree of confidence in the patients' diagnoses. By including different hospitals and a range of specialties we were able to capture a comprehensive record of healthcare usage, which is important as these symptoms often involve more than one bodily system and patients may be attending different clinics. The principal methodological limitation was the retrospective use of medical records for data collection. However, the most important information for the purpose of this study-details of investigations and final diagnosis-are generally well documented in hospital case notes. A further limitation is that although the reliability of this method of recognising medically unexplained symptoms has been shown, ${ }^{7}$ there has been no evaluation of its validity. With the exception of one hospital trust there was a good representation of the health region studied, and the $90 \%$ collection rate for records is comparable with that in previous studies. $^{910}$

We have shown that medically unexplained symptoms account for a substantial proportion of the secondary care usage by frequent attenders. This is the case for most hospital specialties. Complaints that often remain medically unexplained in primary care and in new patients attending clinics-abdominal pain, headache, and low back pain-are also likely to remain medically unexplained in frequent attenders. Van Hemert et al estimated that over half of all patients with new appointments in secondary medical care received a doubtful, or no, medical diagnosis. ${ }^{11}$ Hamilton et al reported rates of medically unexplained
What is already known on this topic

Frequent attenders in all medical settings account for a disproportionate amount of healthcare resources

In primary care, frequent attenders commonly present with symptoms that remain medically unexplained

\section{What this study adds}

Medically unexplained symptoms are also common among frequent attenders in secondary care and present in most specialties

Symptoms that are particularly likely to remain unexplained in this group include gastrointestinal complaints, back pain, and headache

symptoms of $53 \%, 42 \%$, and $32 \%$ in gastroenterology, neurology, and cardiology respectively'; and this finding was confirmed by Nimnuan et al, who looked at seven specialist clinics in one hospital in which $51 \%$ of new patients were diagnosed as having medically unexplained symptoms. ${ }^{10}$ Our figure of $21 \%$ of all consultation episodes in this particular sample shows that while some patients with unexplained symptoms are discharged from secondary care after their assessment, many continue to attend, are often referred on to another specialty, and become frequent attenders in secondary care.

Medically unexplained symptoms are associated with high rates of disability. ${ }^{12-14}$ Patients report poorer levels of physical and social functioning than those who receive a medical diagnosis and spend between 1.3 and 4.9 days in bed each month compared with patients with major medical problems, who average one day or less. ${ }^{12}{ }^{15}$ Despite their increased use of healthcare resources, the management of patients with unexplained symptoms is perceived as unsatisfactory from the perspective of both the patient and the physician. ${ }^{16}$ Also, they may undergo extensive investigation and medical treatment, which may not only be inappropriate but also hazardous. ${ }^{17}$ There is evidence that iatrogenic factors such as inappropriate information, overinvestigation, and overtreatment are common in the management of patients with medically unexplained symptoms, ${ }^{18}{ }^{19}$ and avoidance of these factors forms the mainstay of most advice on their management. ${ }^{20}$ In primary care medically unexplained symptoms and their management have been considered a priority. ${ }^{21-23}$ We have shown that medically unexplained symptoms account for a considerable proportion of presentations in frequent attenders in secondary care and conclude that these patients should be considered a focus for attention.

We thank all of the NHS trusts who agreed to participate in this study and in particular the medical records staff who assisted in retrieval of case notes. We also thank Dr R Hooper for providing statistical advice and helpful comments on the paper.

Contributors: All authors were involved in the planning and design of the study. SR collated and analysed the data and was the principal writer of the paper. SW helped in interpretation of the data and writing of the paper. TC took part in the study design. MH participated in the analysis and interpretation of data and writing of the paper. SR, TC, and MH are guarantors. 
Funding: NHS Executive National Research and Development Programme.

Competing interests: None declared.

1 Zook CJ, Moore FD. High-cost users of medical care. $N$ Engl J Med 1980;302:996-1002.

2 Garfinkel SA, Riley GF, Iannacchinoe VG. High-cost users of medical care. Health Care Financing Review 1988;9:41-52.

3 Wamoscher Z. The returning patient: a survey of patients with high attendance rate. J Coll Gen Pract 1966;11:166-73.

4 Kroenke K, Mangelsdorff AD. Common symptoms in ambulatory care: incidence, evaluation, therapy, and outcome. Am J Med 1989;86:262-6.

5 Bass C, Bond A, Gill D, Sharpe M. Frequent attenders without organic disease in a gastroenterology clinic. Gen Hosp Psychiatry 1999;21:30-8.

6 Fink P. The use of hospitalizations by persistent somatizing patients. Psychol Med 1992;22:173-80.

7 Reid S, Crayford T, Richards S, Nimnuan C, Hotopf M. Recognition of medically unexplained symptoms-do doctors agree? J Psychosom Res 1999;47:483-5.

8 Hotopf M, Mayou R, Wadsworth M, Wessely S. Childhood risk factors for adults with medically unexplained symptoms: results from a national birth cohort study. Am J Psychiatry 1999;156:1796-800.

9 Hamilton J, Campos R, Creed F. Anxiety, depression and management of medically unexplained symptoms in medical clinics. $J R$ Coll Physicians Lond 1996;30:18-20.

10 Nimnuan C, Hotopf M, Wessely S. Medically unexplained symptoms: how often and why are they missed? QJ Med 2000;93:21-8.

11 Van Hemert AM, Hengeveld MW, Bolk JH, Rooijmans HGM, Vandenbroucke JP. Psychiatric disorders in relation to medical illness among patients of a general medical out-patient clinic. Psychol Med 1993;23:167-73.
12 Smith GR Jr, Monson RA, Ray DC. Patients with multiple unexplained symptoms: their characteristics, functional health and health care utilization. Arch Intern Med 1986;146:69-72.

13 Katon W, Lin E, von Korff M, Russo J, Lipscomb P, Bush T. Somatization: a spectrum of severity. Am J Psychiatry 1991;148:34-40.

14 Escobar JI, Burman MA, Karno M, Forsythe A, Golding JM. Somatization in the community. Arch Gen Psychiatry 1987;44:713-8.

15 Wells KB, Stewart A, Hays RD, Burman A, Rogers W, Daniels M, et al. The functioning and well-being of depressed patients: results from the medical outcomes study. JAMA 1989;262:914-9.

16 Lin EHB, Katon W, von Korff M, Bush T, Lipscomb P, Russo J, et al. Frustrating patients: physician and patient perspectives among distressed high users of medical services. J Gen Intern Med 1991;6:241-6.

17 Fink P. Surgery and medical treatment in persistent somatizing patients. $J$ Psychosom Res 1992;36:439-47.

18 Kouyanou K, Pither C, Wessely S. Iatrogenic factors and chronic pain. Psychosom Med 1997;59:597-604.

19 Kouyanou K, Pither CE, Rabe-Hesketh S, Wessely S. A comparative study of iatrogenesis, medication abuse, and psychiatric morbidity in chronic pain patients with and without medically unexplained symptoms. Pain 1998;76:417-26.

20 Wilkie A, Wessely S. Patients with medically unexplained symptoms. $\mathrm{Br}$ J Hosp Med 1994;51:421-7.

21 Karlsson H, Lehtinen V, Joukamaa M. Psychiatric morbidity among frequent attender patients in primary care. Gen Hosp Psychiatry $1995 ; 17: 19-25$.

22 Portegijs PJM, van der Horst FG, Proot IM, Kraan HF, Gunther NCHF, Knottnerus JA. Somatization in frequent attenders of general practice. Soc Psychiatry Psychiatr Epidemiol 1996;31:29-37.

23 Kerwick S, Jones R, Mann A, Goldberg D. Mental health care training priorities in general practice. BrJ Gen Pract 1997;47:225-7.

(Accepted 21 December 2000) 